\section{El rol de las familias españolas con hijos con discapacidad en la inclusión educativa. Una mirada histórico-normativa}

\section{The role of spanish families with children with disabilities in inclusive education. A historical-normative point of wiew}

\section{Palabras clave}

Educación inclusiva, inclusión social, familia, discapacidad, participación, formación.
"Freedom is the freedom to say that two plus two make four. If that is granted, (George Orwell, I984). all else follows".

\section{Consideraciones generales}

\section{Keywords}

Inclusive education, social inclusion, family, disability, participation, training.

\section{Fran J. García-García \\ <garfran2@alumni.uv.es> \\ Departamento de Educación \\ Comparada e Historia de la Educación, Facultad de Filosofía y Ciencias de la Educación, Universidad de Valencia}

\section{Manuel López-Torrijo}

<mlopez@uv.es>

Departamento de Educación

Comparada e Historia de la Educación, Facultad de Filosofía y Ciencias de la Educación, Universidad de Valencia
Para citar:

García-García, F. J. y López-Torrijo, M. (20I6): "El rol de las familias españolas con hijos con discapacidad en la inclusión educativa. Una mirada histórico-normativa". Revista Española de Discapacidad, 4 (2): $219-233$

Doi: <https://doi.org/I0.5569/23405 IO4.04.02.I2>
The Committee of Enquiry into the Education of Handicapped Children and Young People (I978), encabezado por Mary Warnock, acuña el concepto de necesidades educativas especiales (NEE) a finales de la década de los 
setenta. Esta categorización abre la perspectiva de la Educación Especial, hasta hora centrada en el alumnado con discapacidad, e incorpora en este derecho a la educación también a aquellos alumnos que presenten cualquier tipo de necesidad -temporal o permanente, grave o moderada- que dificulta su acceso al aprendizaje y la participación educativa plenas. Es la quiebra de toda segregación y el inicio de una educación completa y de calidad para todos. Sin embargo, la recategorización y la modificación de las expectativas sobre los resultados del aprendizaje de las personas con NEE advienen recientemente. Antes de esto, la historia evidencia unas prácticas abusivas y exterminadoras hacia las personas con discapacidad (López-Torrijo, 20I 5) que tal vez todavía guarden relación con la mentalidad social e incluso educativa actuales. "En el recuerdo del pasado se pueden encontrar los gestos que han dejado su huella en algunas de nuestras actitudes, prejuicios, mentalidades, inercias... y que tanto condicionan nuestra conducta” (López-Torrijo, I999: I7). Pero recordemos la filosofía de Epicuro con el fin de revisar nuestro presente en la línea con el giro copernicano que está aconteciendo en estos momentos. Si nadie es demasiado joven ni mayor para empezar a reflexionar, ¿hasta cuándo vamos a prolongar la segregación y la marginación, aunque se presenten ahora matizadas con propuestas (modelos, formatos, fórmulas, experiencias) aparentemente humanitarias?

Recientemente, el reconocimiento a ese derecho a la educación aparece recogido en diversas Declaraciones Internacionales. Pese al carácter meramente orientativo, y sólo exigible en el caso de las Convenciones, estas Declaraciones juegan una función importante. Por una parte, visibilizan una filosofía educativa que recoge las sensibilidades y conciencias recientes. Por otra, orientan las políticas educativas desde un imperativo internacional. En parte pudieren constituir meras declaraciones de buenas intenciones, mientras que muchas de las propuestas que recogen resultan sumamente valiosas de cara a su aplicación. En cualquier caso, el último documento sobre educación inclusiva (EI) de la Unesco (20 I 5 ), la Declaración de Incheón, pone de manifiesto que la participación sigue siendo un problema de ferviente actualidad (artículos 7, I 2 y I7), junto a la exclusión o las dificultades de aprendizaje. Tengamos presente que las declaraciones internacionales bien podrían suponer un punto de anclaje entre las dos dimensiones -teoría y praxis-, cobrando por tanto representación en ambas dos esferas. Desde esta perspectiva, la participación implica a la familia, la comunidad educativa, las administraciones públicas y la sociedad en suma, entre otras audiencias de interés educativo (Adelman y Taylor, 2007). La atención del presente documento girará en torno a las familias. En este sentido y buscando las raíces de la situación presente, nos surge una primera cuestión: si la preocupación por la implicación es fruto de la inercia histórica, recreada en el seno familiar; si es producto de la era moderna y su particular tinte de individualismo (Sennett, 2006, 2010); o si se nutre de ambas cuestiones.

Tal vez lo que ocurra es que la inclusión no se termina de comprender y asumir. Desde esta perspectiva, la razón de ser de la discapacidad quizás no sea tan relevante aisladamente. La discapacidad, como variable, cobra sentido a partir de su función. "La relación entre variables (expresada por lo común, aunque no necesariamente, como una ecuación) constituye el concepto de función" (Watzlawick et al., 2OI 2: 25-26), rechazando la idea material clásica de los números para abrazar la probabilidad virtual. El movimiento en una dirección es relativo irreparablemente a un punto de partida. Por tanto, la definición de una variable cobra sentido en su relación con un contexto, no de manera aislada. Esto mismo entendía Frondizi (I972) en su propuesta axiológica y Brofenbrenner (I979, 2002) en su teoría ecológica. De este modo se articula un razonamiento que parte del individualismo actual. Apelando al logos, lo más sensato sería afirmar que 'yo' soy 'yo'. No obstante, 'yo' también soy 'tú' y 'él/ella', en la medida en que son una influencia para 'mí', nutriendo el propio ser a partir de éstos para completar el ‘yo’. Si no es así, ¿qué sentido alberga la 
educación? Aunque si 'yo' soy 'yo', 'tú' y ‘él/ ella', necesariamente también soy 'nosotros', 'vosotros' y 'ellos/ellas' porque existimos múltiples personas. En consecuencia, 'yo' soy uno y soy muchos, en este instante ' $x$ ' y en el siguiente ' $y$ ', puesto que el ser humano está sujeto al cambio constante. Éste es el valor de la diversidad, intrínseco a la condición humana y, por ende, presente en la educación. Porque si fuésemos iguales ¿quién enseñaría a quién?

Todos tenemos varias dis-capacidades, y, de igual manera, las personas llamadas discapacitadas -por su mera diversidad funcional, o por su categorización social y profesional- también tienen diversas capacidades. Si, en lugar de enfrentar nuestras diferencias o intentar imponer al resto nuestros posicionamientos ideológicos, las personas nos sumamos mediante una relación basada en la equidad y la digna consideración de la alteridad, indudablemente ganamos en riqueza. "Sobre todo: correspondemos bien a la naturaleza, si necesitando nosotros de que muchos nos ayuden, ayudamos también a otros muchos" (Vives, I78 I: 33). En este sentido, probablemente sean aquellas familias que desconozcan la inclusión y la diversidad quienes hagan la distinción entre familias con y sin NEE.

En síntesis, el tiempo presente reclama la renovación y recategorización social y educativa, en pro de una educación para todos sin excusas históricas, políticas, sociales, o de cualquier otra índole. Concretamente, se exige la seguridad de una educación familiar en base a los principios expuestos, pues "aquello que ocurra dentro del contexto familiar en los primeros años va a tener una influencia decisiva en la vida posterior" (Cánovas y Sahuquillo, 20I4: 22). Tengamos presente que "lo que se aprende en la familia tiene una indeleble fuerza persuasiva, que en los casos favorables sirve para el acrisolamiento de principios moralmente estimables que resistirán luego las tempestades de la vida" (Savater, 1997: 69).

\section{Panorama normativo ${ }^{1}$}

"Disability is part of the human condition", según la Organización Mundial de la Salud (WHO, 20II: 26I). Este es un principio político internacional, no únicamente analítico: todos somos discapacitados. Matizando, García Molina (20I3) apunta que ser una persona excluida no es sinónimo de estar en situación de exclusión. Por razonamiento análogo, ser una persona discapacitada no equivaldría a ser alguien en situación de discapacidad. Todos presentamos limitaciones y esto obedece a un locus de causalidad interno. No obstante, estar en situación de discapacidad es una cuestión contextual. De esta forma, la participación e implicación de las familias con hijos con discapacidad, entre otros factores, es considerada internacionalmente como un potente factor ambiental de cara a valorar la diferencia entre la discapacidad y la situación de discapacidad (WHO, 200I).

"Environmental factors make up the physical, social and attitudinal environment in which people live and conduct their lives. These factors are external to individuals and can have a positive or negative influence on the individual's performance as a member of society, on the individual's capacity to execute actions or tasks, or on the individual's body function or structure" (WHO, 200I: I6).

Es importante señalar cómo la Organización Mundial de la Salud mantiene esta idea durante diez años, afirmando en 20Ir: "The functioning of a child should be seen not in isolation but in the context of the family and the social environment" (WHO, 20II: 36). ¿Es acaso esta insistencia global un indicador de la carencia participativa de estas familias? Más allá de esto,

I. Los documentos internacionales han sido localizados y analizados en su idioma original, en la medida de lo posible. Por este motivo la mayor parte de estas fuentes han sido tratadas en lengua inglesa, atendiendo a las puntualizaciones de los organismos internacionales sobre su origen. Esta decisión queda justificada, no únicamente por la originalidad de las fuentes, sino por las implicaciones hermenéuticas del presente trabajo. 
la Organización de las Naciones Unidas (UN) lleva apostando desde I994 por el contrapunto de la participación familiar: "States should promote the full participation of persons with disabilities in family life" (UN, I994, art. 9: I8). Este criterio refuerza todavía más la idea de la discapacidad como función, en constante interrelación y sujeta a modificaciones.

Desde un punto de vista supranacional, el Consejo de Europa también señala la importancia de la participación familiar, comprendiendo la educación como un motor de consecución de la inclusión social. Es más, califica la inclusión del alumnado con NEE en aulas ordinarias como una acción beneficiosa para el total de alumnos (Consejo de Europa, 2006, art. 3.4).

La WHO (20II) reconoce, por otra parte, las limitaciones formativas y las necesidades de información de las familias con hijos con discapacidad. Por este motivo, considera el apoyo formativo e informativo como una vía de empoderamiento para las familias. Una vez debidamente formadas, la Unesco (2005, 2009) considera el núcleo familiar como un valioso recurso para la comunidad educativa y la inclusión de los sectores más excluidos. La Organización de Naciones Unidas (ONU) lleva avalando este ejercicio desde I975, como un derecho de las personas con discapacidad y sus familias. De manera expresa, se afirma: "Disabled persons, their families and communities shall be fully informed" (UN, I975, art. I3: 89).

Como puede observarse, se requiere una línea de acción sociopolítica y una puesta en marcha e implementación de programas educativos. Desde I994, la ONU viene haciendo responsables a los estados miembros del desarrollo de políticas y programas donde se intervenga en relación a los objetivos mencionados desde la multidisciplinaridad. Para ello, la escuela es un escenario clave junto a la atención y aprendizaje tempranos, como señala la Unesco en 2009. Más aún, "Parents and families must be involved in the development and monitoring of the individualized education plan for their child, both at support centers and at regular school." (Unesco, 2009: 63).

En concordancia con lo expuesto, la Estrategia Europea sobre Discapacidad 2010-2020 tiene como objetivo dotar de capacidades a las personas con diversidad funcional, a fin de posibilitar el disfrute de todos sus derechos y el beneficio pleno de su participación en la economía y la sociedad europeas. Se trata de superar barreras en pro de la igualdad de oportunidades, basándose en los siguientes ámbitos de actuación: accesibilidad, participación, igualdad, empleo, educación y formación, protección social, sanidad y acción exterior. Esto se llevará a cabo mediante la sensibilización, el apoyo financiero, y la recopilación y descripción de datos (Comisión Europea, 20I0). Comprobamos, pues, cómo la concienciación social constituye una herramienta tan necesaria como la financiación y la investigación. A diferencia de estas dos últimas -imprescindibles para la continua implementación y desarrollo-, el producto de la inercia histórica y del individualismo actual, plasmados sobre la necesidad de sensibilización, conforman una cuestión que urge superar. Igualmente, una inquietud por comparación es que los objetivos de Europa van en sintonía con lo descrito a partir de documentos de los organismos internacionales. En cualquier caso, observamos que tanto las inquietudes como las medidas sugeridas tienen plena coincidencia en los planos europeo y global.

De forma similar, el Consejo Europeo recomienda la acción "to promote the rights and full participation of people with disabilities in society (...) involving, in particular, nongovernmental organisations of people with disabilities" (Consejo de Europa, 2006: I). Recordemos que Warnock ya otorgó en 1987 un papel esencial a las organizaciones del tercer sector de acción social conformadas por las personas con discapacidad y sus familias. En sintonía con las necesidades formativas de estas familias, la Unesco (200I: 87) sostiene que "the international evidence suggests that organisations of and for families are a highly effective way of building family capacity". Y 
añade: "Ministries of education should formulate educational policy and planning in consultation with families and organizations of persons with disabilities and develop programmes of education which enable children with disabilities to attend their local pre-school, primary, or secondary schools. (...) Decisions on policy and practices for the education of children with disabilities should be made in collaboration with education officials, schools, parents, communities, families and organizations of people with disabilities” (Unesco, 2009: 29-30).

Lamentablemente, las políticas españolas no han plasmado en sus propuestas las indicaciones internacionales. En lo conceptual, no se comprende la discapacidad como una condición humana (WHO, 20II) sino como "una situación que resulta de la interacción entre las personas con deficiencias previsiblemente permanentes y cualquier tipo de barreras que limiten o impidan su participación plena y efectiva en la sociedad, en igualdad de condiciones con las demás." (Real Decreto Legislativo I/20I3, de 29 de noviembre, art. 2. a). Sí se acoge, por otro lado, la idea de la discapacidad como una variable cuya función implica una relación contextual. En lo referente a la dimensión educativa, la normativa nacional comprende por NEE las de aquel alumnado "que requiera, por un periodo de su escolarización o a lo largo de toda ella, determinados apoyos y atenciones educativas específicas derivadas de discapacidad o trastornos graves de conducta" (Ley Orgánica 2/2006, de 3 de mayo, art. 73). Esta idea de NEE coincide con las bases del concepto acuñado en el Informe Warnock en I978. Por ende, los beneficiarios de la aplicación legal son los mismos que cumplen las características descritas en el mencionado informe, estableciéndose una sintonía histórica y con los países de nuestro contexto.

Los derechos constitucionales a la educación (Constitución Española de I978, art. 27) y a la igualdad (Ibídem, arts. 9.2 y I4) de los alumnos con discapacidad implican una adecuada formación de los profesionales, que habrán de trabajar interdisciplinarmente con ellos (Real
Decreto 696/I995, de 28 de abril, art. 5.2. y Real Decreto Legislativo I/20I3, de 29 de noviembre, art. I2.I). Se apuesta por la inclusión en aulas ordinarias en pro de una educación inclusiva de calidad y gratuita, que garantice una igualdad de condiciones (Real Decreto 696/I995, de 28 de abril, art. 3.2. y Real Decreto Legislativo I/20I3, de 29 de noviembre, art.I 8.I) en espacios debidamente habilitados en función de las necesidades educativas (Real Decreto 696/I995, de 28 de abril, art. 5.2.). Esto está ligado a su derecho a la igualdad en todos los ámbitos de la vida (Real Decreto Legislativo I/20I3, de 29 de noviembre, art. 7). Sin embargo, la igualdad es un concepto considerado insuficiente por quienes plantean su superación mediante el principio de la equidad, comprendida como la igualdad de oportunidades en lo respectivo a supervivencia, desarrollo y satisfacción de potencialidades (Unicef, 20II). El principio de equidad sí se contempla en la normativa española en materia de educación (Ley Orgánica 2/2006, de 3 de mayo, art. I. b), no obstante, su incorporación a la reglamentación inmediata no es completa todavía.

Por otro lado, es preciso contemplar con la misma consistencia el derecho a la libertad (Constitución Española de I978, arts. 9.2 y I7), y concretamente a la libertad de las familias para elegir el centro docente al que habrán de asistir sus hijos (Ibídem., art. 27.3). El Real Decreto 696/I995, de 28 de abril, recoge el derecho a la elección de centro para las familias con hijos con NEE, en el art. 9.I. Este derecho queda asegurado en tanto que estas familias están en condición preferente de cara al acceso de sus hijos en un centro de enseñanza (Ley Orgánica 8/20I3, de 9 de diciembre, modificación del art. 84.2 de la Ley Orgánica 2/2006, de 3 de mayo).

Es preciso relacionar el ejercicio de este derecho con otros planteamientos de la Ley Orgánica 8/20I3, de 9 de diciembre. Si a la par se promueve la excelencia, la diferenciación de los centros (preámbulo V; art. I 22 bis. 3) y se plantea premiar a dichos centros por los resultados educativos que presenten (art. 6 bis. 5 y I 22 bis. 3; modificación del art. I 20.3 y 2 I.3 de la Ley Orgánica 2/2006, de 3 de mayo), puede deducirse con rotundidad que 
esta filosofía de la "excelencia por resultados" es una clara invitación a que los directores de los centros -cuyas competencias han sido claramente incrementadas en detrimento de las de los Consejos Escolares- tiendan a eliminar el alumnado con discapacidad de sus aulas, en previsión de que baje la media de sus calificaciones.

Por otra parte y en coherencia con la educación inclusiva, los resultados no pueden ser medidos en base a una prueba única, pasada de forma puntual, como se propone, tanto en las pruebas diagnósticas, como en las evaluaciones finales individualizadas (modificación del art. 20.2 y 2I.3 de la Ley Orgánica 2/2006, de 3 de mayo). La evaluación inclusiva exige el seguimiento de un proceso global, partiendo de la situación inicial del alumno, atendiendo a sus necesidades, mediante la personalización de los recursos y medias, y valorando el progreso integral. En este sentido, las propuestas mencionadas de la Ley Orgánica 8/20I3, de 9 de diciembre, están en clara contradicción con los principios inclusivos que se plantean efusivamente en el art. I y suponen un claro atentado a los derechos del alumnado con discapacidad y a la educación inclusiva real y de calidad que exigía el CERMI ya en 20 Io.

El pleno ejercicio de la libertad requiere de un proceso de individuación (Fromm, 2009) que asigne a las familias una mayor responsabilidad sobre sus actuaciones. De este modo, la libertad no es factible sin una equidad establecida a priori, que garantice el desarrollo personal. Es necesario, por ello, que la normativa contemple que: "Las personas con discapacidad y sus familias tienen derecho a unos servicios y prestaciones sociales que atiendan con garantías de suficiencia y sostenibilidad sus necesidades, dirigidos al desarrollo de su personalidad y su inclusión en la comunidad, incrementando su calidad de vida y bienestar social” (Real Decreto Legislativo I/20I3, de 29 de noviembre, art. 48).

Es en este punto donde la formación a las familias con NEE resulta crucial. En cambio, la normativa contempla más ampliamente el derecho a la información. Estas familias tienen derecho a informarse sobre la escolarización de sus hijos (Real Decreto 696/I995, de 28 de abril, art. 9.I) y se les dotará de recursos económicos que posibiliten el acceso a los productos y servicios de la sociedad de la información (Real Decreto I494/2007, de I 2 de noviembre, Disposición adicional segunda. a). En base a esto, podría afirmarse que se les está asignando una responsabilidad a las familias -la de informarse y decidir libremente-, a partir de la cual tienen derecho asimismo a la participación. Por otra parte, se procurará la colaboración de estas familias en el proceso de identificación de las necesidades y en la acción preventiva o compensadora (Real Decreto 696/I995, de 28 de abril, art. 9.4). Se entiende que "las familias son las primeras responsables de la educación de sus hijos" (Ley Orgánica 8/2013, de 9 de diciembre, Preámbulo II, p. 978 59). Pero, ¿cómo decidir e involucrarse adecuadamente sin una formación previa y completa que establezca los criterios de selección y documentación?

En cuanto a los planes de acción, la Estrategia Europea sobre Discapacidad 2010-2020 se plasma en la Ley Orgánica 8/20I3, de 9 de diciembre (Preámbulo V), pretendiendo hacer extensible la modificación sobre la Ley Orgánica 2/2006, de 3 de mayo, también al alumnado con discapacidad, pero sin mencionar a sus familias. Pese a esto, únicamente se recogen medidas de flexibilización y alternativas metodológicas (Ley Orgánica 8/2013, de 9 de diciembre, modificación de los arts. I9.4, 26.6 y 34.2), la participación del alumnado con discapacidad (Ibídem, modificación del art. 27.4), accesibilidad en la admisión en las enseñanzas universitarias (Ibídem, modificación del art. 38.3) y la igualdad de oportunidades, no discriminación y accesibilidad universal (Ibídem, modificación de los arts. 68.2 y 69.4). En lo relativo a las familias y al margen del acceso al centro anteriormente comentado, su participación la deberá fomentar el director del centro docente (Ibídem, modificación del art. I32. g), pudiendo éstas plantear propuestas (Ibídem, Disposición final segunda. Tres) a partir de sus asociaciones ${ }^{2}$ (Ibídem, modificación del art. I I9.4).

2. No viene especificado qué tipo de asociaciones o si han de ser externas o internas al centro docente. 
Definitivamente, se contempla cómo la normativa española no recoge los planteamientos de los organismos a los que pertenecemos o de los acuerdos internacionales que suscribimos.

"Una buena ley cumple una función pedagógica, en cuanto que descubre derechos y recursos de los que el usuario a veces es desconocedor. Por el contrario una mala ley oculta y aplaza el ejercicio de tales derechos. El legislador debiera ir por delante de las necesidades y no ser un lastre de las presiones sociales" (López-Torrijo, 200I: I I I).

Tal vez ese clima individualista, forjado sobre un enfoque economicista de las políticas (Iyanga Pendi, 2003), siga llevando a pensar que “aunque es más hermosa y más útil al Estado la práctica política que la que se refiere a asuntos comerciales, nada dicen de aquella, mientras que todos se afanan por convertir el arte de hablar ante un tribunal en tema de sus tratados (Aristóteles, 20I 2: 48).

\section{El rol de las familias con hijos con discapacidad en la inclusión educativa}

En la medida en que las declaraciones internacionales puedan ser representativas tanto de las teorías como de las políticas, parece razonable utilizarlas, en primera instancia como una referencia para determinar los roles de las familias con hijos con NEE derivadas de una discapacidad. En cuanto a la normativa nacional, según López-Torrijo (I993), “suele ser lamentablemente frecuente el desconocimiento entre enseñantes y familias de este contexto legislativo, produciéndose situaciones de desconcierto, indefensión o despreocupación, que, en parte, son debidos a esta ignorancia. (...) Además la legislación, no solo cuenta con las normas, actuaciones y prácticas puntuales, sino que también deja translucir algo de ese espíritu y de esa ideología que la alienta”.
De este modo y atendiendo al desarrollo de los documentos internacionales, los planteamientos educativos, pedagógicos, incluso sociales, debieran empezar por superar un enfoque clínico -entendido como la actuación terapéutica y aislada sobre una patología o anormalidad individual y llevada a cabo por un profesional específico- y alcanzar un enfoque pedagógico e inclusivo, entendiendo por tal la actuación interdisciplinar de todo el contexto educativo de la persona (familia, profesionales, instituciones, etc.) sobre la globalidad de dicha persona y su contexto social. En esta línea, si la discapacidad es una condición humana (WHO, 20II) que no está contemplando la normativa española, ¿no contribuye esto a un mayor esfuerzo de las familias con hijos con diversidad funcional para valorar sus limitaciones en la participación social y política? Romper con la idea de la Organización Mundial de la Salud supone cuestionar si la discapacidad de unos cuantos es tema de interés social o no y, por tanto, ha de haber o no una intervención pública. La normativa nacional podría inducir a la creencia del mito de las familias con y sin NEE. Así van cobrando sentido las cuestiones que se planteaban hace unos años:

“¿Qué papel pueden desempeñar las personas con limitaciones en esta sociedad que impone un ritmo frenético tanto en lo físico como en lo mental para poder desenvolverse con libertad y autonomía? ¿Pueden quedarse al margen al no poder superar las barreras que la sociedad pone a su desarrollo personal y social? ¿ $\mathrm{O}$ pueden rebelarse ante la situación injusta que la sociedad les impone?

Son cuestiones que pueden acercarnos a una comprensión más profunda de la discapacidad entendida, no como una patología individual, sino como «una cuestión o asunto social», que no solo considera las consecuencias provenientes de la deficiencia o daño que afecta a la persona sino que incluye también las condiciones sociales (culturales, económicas, jurídicas, políticas, etc.) que aparecen como impedimentos o barreras (de todo tipo) acentuando las diferencias o bien, no ofreciendo alternativas de superación o promoción, e incrementando, si cabe, las 
dificultades de las personas" (Vega Fuente, 2003: 28).

Por estos motivos, una función de las familias en sus organizaciones del tercer sector sería desmentir esta creencia mediante la recategorización de la discapacidad en la normativa española, más acorde al sentido internacional. Se trata, en gran parte, de romper con las ataduras del pasado y salvar las barreras del presente.

Previamente al logro de este cambio, las familias han de ser conscientes de su relevancia como institución. Se les otorgan responsabilidades y el derecho a la libertad para tomar decisiones y actuar. Es decir, las familias participan necesariamente de la dinámica educativa y social. Ahora bien, se ha contemplado cómo la normativa nacional e internacional llama a la participación familiar constantemente. Ya fuere por ausencia de oportunidades o por pura apatía, la propia insistencia de la normativa nacional, junto con las disonancias entre sus planteamientos y los de los organismos internacionales, evidencian la insuficiencia de la participación de las familias.

Ello nos lleva a plantear los pasos previos de la información y formación de las familias. La normativa aboca a las familias españolas con hijos con discapacidad más a exigir derecho a la información que a su participación plena en educación total en sí. Indudablemente, resulta difícil en la sociedad actual no encontrar informaciones diversas (Escudero Muñoz, 200I), teñidas de ideología, de intereses sociales, políticos, económicos, etc. Entonces, ¿cómo actúan las familias en beneficio de la educación inclusiva sin una mínima formación? La implicación familiar va de la mano con la formación. Si no, no se comprende su coherencia.

Ciertamente, partimos del supuesto evidente de que la participación de las familias comparte los intereses de la inclusión educativa, puesto que este fenómeno se traduce en la supresión de barreras limitadoras (Booth y Ainscow, 20I I; Echeita Sarrionandia y Ainscow, 20I I;
Sandoval Mena et al., 20I2). La inclusión de las familias en la toma de decisiones sobre las esferas social y educativa constituye una potente medida de atención a la diversidad (Arnaiz, 2005), desembocando así en la resolución de la necesidad de desarrollo de una educación familiar en calidad de contexto significativo. Con todo, la familia es también responsable y beneficiaria de la inclusión (López-Torrijo, I993).

Es por todo ello que una necesidad y demanda inicial de las familias consiste en exigir una formación suficiente para poder ejercer su participación bajo sus intereses. Esto les acercaría al ejercicio pleno de su derecho a la libertad, siendo conocedoras de las implicaciones y del alcance de sus decisiones y actuaciones. De hecho, las propias familias, desde el Comité Español de Representantes de Personas con Discapacidad (CERMI, 2003), estiman necesario el asesoramiento técnico.
"Considero la participación de los padres como uno de los ejes fundamentales del futuro del niño con discapacidad, junto a la prevención y al diagnóstico y atención tempranos. Estoy plenamente convencido de que el éxito de la integración pasa fundamentalmente por la institucionalización de programas de apoyo para las familias que garanticen la adecuada participación de los padres en el proceso educador y rehabilitador de sus hijos" (López-Torrijo, 200I: I I 5 ).

Pero las necesidades formativas de las familias de hijos con discapacidad incluyen y van más allá de las que precisa cualquier otra familia. Incluso para el propio proceso de la aceptación -siempre realista, constructiva y solidariade la discapacidad de su hijo, precisan, a la par que del apoyo psicopedagógico, de una información completa de todos los aspectos relativos a dicha discapacidad: médicos, educativos, rehabilitadores, tecnológicos, sociales, asistenciales, laborales, lúdicos, etc. Sin una adecuada formación los padres no estarán capacitados para participar en la educación de su hijo en la medida en la que éste lo precisa. Y ello, tanto en el marco interno de la familia como en el institucional del centro escolar. En 
otras palabras: hasta que no se institucionalice la información y adecuada formación de los padres, no es posible esperar su insustituible participación en el proceso de la educación de su hijo discapacitado.

El escenario sustancial para la participación de las familias son los centros docentes, donde el efecto de la colaboración familiar surte amplios beneficios sobre el proceso de aprendizaje y desarrollo de los hijos (Robinson y Harris, 20I4). Conforme a la normativa, se ha observado que la participación de las familias en los centros habrá de ser fomentada por la figura del director. No obstante, las familias tienen sus propios organismos de representación y participación, internos y externos a los centros de enseñanza. A fin de conseguir la necesaria educación inclusiva, parece más lógico que sea desde las organizaciones de familias desde donde se sustancien los modos de implicación familiar en el funcionamiento del centro docente.

Téngase presente la relevancia que se les otorga en los documentos internacionales a las familias. La Ley Orgánica 8/2013, de 9 de diciembre, recoge entre sus principios el refuerzo de la capacidad de gestión de la Dirección de los centros escolares (Preámbulo, VI y VII). Se establece la necesaria aprobación del director para la obtención de recursos complementarios (Ibídem., modificación del art. I22.3 de la Ley Orgánica 2/2006, de 3 de mayo), su autonomía para la adaptación de recursos humanos a las necesidades del centro (Ibídem., añadido del art. I 22 bis., 4), la dirección y coordinación de todas las actividades (Ibídem., modificación del art. I32. b), el fomento de la participación de las familias (Ibídem., modificación del art. I32. g), de evaluaciones internas (Ibídem., modificación del art. I32. h), la aprobación de proyectos (Ibídem., modificación del art. I32. 1) y programaciones (Ibídem., modificación del art. I32. m), así como la admisión de alumnos al centro de enseñanza (Ibídem., modificación del art. I32. n).

Contrariamente a lo que dicta la ley, podríamos considerar que estas competencias resultan excesivas para un director en un centro de enseñanza. Tampoco el director del centro conoce mejor al alumnado con NEE que los propios docentes como para decidir con pleno poder sobre la toma de decisiones respecto a los recursos. Por todo ello, una medida de equilibrio de poderes en los centros y de atención a las NEE del alumnado de una manera más horizontal consistiría en regular un reparto de funciones y competencias más equitativo. Sin duda el propio Consejo Escolar y las diferentes Comisiones (de Coordinación Pedagógica, Servicios Psicopedagógicos, Comisión de Atención a la Diversidad, asociaciones de familias, etc.) serían estamentos más participativos y democráticos que la atribución unipersonal que realiza la Ley Orgánica 8/20I3, de 9 de diciembre.

Una vuelta de tuerca a la igualdad, no tan novedosa como parece, es la equidad. Aristóteles (2009) distingue la equidad de la justicia. Así, viniendo la ley recogida en términos generales para el total de la población, la equidad, conforme a la justicia, consiste en la atención a las especificidades de cada cual. Por esto, el filósofo considera la equidad superior a la justicia misma.

En el contexto actual diríamos que, más allá de la normativa, son los profesionales los encargados de asumir y desarrollar la equidad. "Consideramos que es el profesorado el protagonista de la implementación de las prácticas educativas inclusivas" (Lledó Carreres y Arnaiz Sánchez, 20I0: 98). Por lo tanto, su formación resulta imprescindible y, en concordancia con la temática analizada, es inexcusable su capacidad para cooperar con las familias.

Una mirada a los planes de estudios evidencia una formación más amplia para los maestros de educación infantil (BOE, Orden ECI/38 54/2007, de 27 de diciembre) y primaria (BOE, Orden $\mathrm{ECI} / 3857 / 2007$, de 27 de diciembre) respecto al profesorado de educación secundaria (BOE, Orden ECI/3858/2007, de 27 de diciembre). Además, en lo que respecta a la formación inicial del profesorado de educación secundaria en materia de educación inclusiva, la investigación en España concluye en una 
insuficiencia rotunda (López-Torrijo y MengualAndrés, 2015 ; Sánchez Palomino, I997, 2007).

El derecho de todos los ciudadanos a la educación que recoge el artículo 27 de la Constitución Española de I 978 se establece mediante criterios de obligatoriedad y gratuidad. ¿Se deduce de aquí que la formación de los profesionales encargados de la educación obligatoria ha de ser también de obligado cumplimiento? En caso contrario, la ausencia o insuficiencia de una preparación de los profesionales podría estar faltando a un derecho constitucional, precisamente por su falta a los principios propios de la inclusión.

En respuesta a las carencias formativas del profesorado, otro de los roles de las familias con hijos con necesidades educativas especiales y sus órganos de representación, consistirá en exigir la formación de los profesores de cara a la colaboración con ellas. En cualquier caso, entendemos que la colaboración entre familias con hijos con necesidades educativas especiales y profesionales, decretada en la normativa nacional (BOE, Real Decreto 696/I995, de 28 de abril, art. 5.2. y BOE, Real Decreto Legislativo I/20I3, de 29 de noviembre, art. I 2.I), no se cumple como debiera. Por ello, planteamos que la normativa educativa debiera especificar con más detalle el derecho a una participación plena, a la par que sugerir diferentes propuestas de participación.

Haciendo alusión a la novela de George Orwell (I96I), citada al inicio del presente documento, efectivamente la libertad pudiere consistir en decidir que dos y dos son cuatro. Sin embargo, I984 pone de relieve la complejidad del acceso a la información para las personas que no son conocedoras de las dimensiones que ello conlleva. El conocimiento se presenta como un pilar fundamental ante la inercia histórica, la articulación de políticas y la coexistencia de diversos intereses. Para el ejercicio de la libertad es necesaria la equidad -que habrán de afianzar interdisciplinarmente las figuras profesionales de múltiples ámbitos- que supone la formación de las familias con hijos con necesidades educativas especiales para informarse y tomar decisiones bajo sus propias necesidades. Es justamente así como se comprende desde el CERMI (20I0), porque sin una adecuada formación de las familias no hay inclusión educativa posible.

\section{Conclusiones y líneas de acción emergentes}

El reconocimiento normativo del derecho de las familias a la educación de sus hijos exige su concreción, al menos, en dos cuestiones básicas: cómo puede llegar a ejercerse dicho derecho $\mathrm{y}$, segundo, las funciones que las familias deben desempeñar al respecto. Las familias cuentan con la presencia de organismos en los que encuentran su representación, a partir de los cuales poder actuar e influir sobre las políticas y prácticas que acontezcan. Al amparo de estas organizaciones, algunos de los roles sociopolíticos de las familias con hijos con diversidad funcional pueden ser:

- La recategorización del concepto de discapacidad en la normativa nacional, hacia los principios expuestos por la $\mathrm{WHO}$ (20II).

- La exigencia de una información y formación a las familias con hijos con discapacidad, como capacitación básica para el ejercicio de los mencionados derechos a una educación ajustada a sus necesidades: la educación inclusiva.

- El consenso de estas familias con el centro docente respecto a los modos de participación, conforme a sus necesidades.

- La reivindicación de una formación del cuerpo docente, tanto inicial como continua, para el afianzamiento de la inclusión, y concretamente para la cooperación entre las familias y el profesorado.

Es preciso que las políticas nacional y europea transiten hacia una descentralización, tomando como referencias la proximidad y efectividad que aportan al usuario las instituciones 
regionales y locales. En el marco de una responsabilidad compartida en el ejercicio de una educación inclusiva, resulta imprescindible integrar la participación de las familias. En éste, el marco de una responsabilidad compartida sobre el fenómeno de la inclusión, resulta imprescindible contemplar a las familias (Carbonell Peris, 2009). "A menudo las propias familias deben compensar a su coste las limitaciones de la propia legislación, de la administración, de los servicios y de los propios profesionales”. (López-Torrijo, 2005: 6I).

Por ello es momento ya de poner punto final a esta situación de limitación, paternalismo, secundariedad o negación en la participación de los padres y hacer efectivo el derecho reconocido de manera voluntarista en las declaraciones internacionales, haciendo que sea tan real y efectivo como precisan los hijos con discapacidad y sus familias. 
Referencias bibliográficas

Adelman, H. y Taylor, L. (2007): Fostering School, Family and Community involvement. Effective Strategies for Creating Safer Schools and Communities (en línea). <http://smhp.psych. ucla.edu/publications $/ 44 \%$ 2oguide $\% 207 \% 20$ fostering $\%$ 2oschool $\%$ 2ofamily $\%$ 2oand $\% 20$ community \% 2oinvolvement.pdf>, acceso 20 de febrero de 2016 .

Aristóteles (20I2). Retórica. Madrid: Alianza Editorial.

Aristóteles (2009): Ética nicomaquea. Ética eudemiana. Madrid: Prisa Innova S. L.

Arnaiz, P. (2005): Atención a la diversidad. Programación curricular. Costa Rica: Universidad Estatal a Distancia.

Booth, T. y Ainscow, M. (201 I): Index for inclusion. Developing learnings and participation in schools. Bristol: Center for Studies on Inclusive Education.

Bronfenbrenner, U. (2002): La ecología del desarrollo humano: experimentos en entornos naturales y diseñados. Barcelona: Paidós.

Brofenbrenner, U. (1979): The Ecology of Human Development. Cambridge: Harvard University Press.

Cánovas Leonhardt, P. y Sahuquillo Mateo, $\mathrm{P}$ (20I4): "La familia como contexto de desarrollo y educación”, en Cánovas Leonhardt, P. y Sahuquillo Mateo, P. (coords.): Familia y menores. Retos y propuestas pedagógicas. Valencia: Tirant Humanidades.

Carbonell Peris, R. (2009): Educación especial en Europa. Valencia: Tirant lo Blanch.

CERMI (2OIO): Manifiesto del CERMI estatal con motivo del día internacional y europeo de las personas con discapacidad (en línea). <https:// www.google.es/

url? $s a=t \& r c t=j \& q=\&$ esrc $=s \&$ source $=w e b \&$ $\mathrm{cd}=3 \&$ ved $=0$ CCsQFjACahUKEwjI7ZLogN HIAhUCoRoKHcVZBp4\&url=http \% 3 A \% 2F\% 2 Fboletin.cermi.es \% 2 Frender.aspx $\%$
${ }_{3}$ Ffichero\% ${ }_{3}$ D6268usg=AFQjCNF 3 JLWE bFXQ2 WfntCvsQ 5 WC_qZuoQ\&sig2 $=5 \mathrm{y}$ gGe_35BCoAvIcinaubg\&cad=rja>, acceso 20 de febrero de 2016 .

CERMI (2003): Plan del CERMI para la protección de las familias con personas discapacitadas (en línea). < http://www.cermi. es/es-ES/ColeccionesCermi/Cermi.es/Lists/ Coleccion/Attachments/67/5planfamilias.pdf $>$, acceso 20 de febrero de 2016.

Comisión Europea. Communication from the commission to the european parliament, the council, the european economic and social committee and the committee of the regions. European Disability Strategy 2010-2020: A Renewed Commitment to a Barrier-Free Europe, European Commission, I 5 de noviembre de 20 IO.

Committee of Enquiry into the Education of Handicapped Children and Young People (I978): The Warnock report (en línea). <http:// www.educationengland.org.uk/documents/ warnock/warnock I978.html>, acceso $20 \mathrm{de}$ febrero de 2016.

Consejo de Europa. Recommendation Rec(2006)5 of the Committee of Ministers to member states on the Council of Europe Action Plan to promote the rights and full participation of people with disabilities in society: improving the quality of life of people with disabilities in Europe 2006-20I 5. Council of Europe, 5 de abril de 2006.

Echeita Sarrionandia, G. y Ainscow, M. (20I I): "La educación inclusiva como derecho. Marco de referencias y pautas de acción para el desarrollo de una revolución pendiente”. Tejuelo, I2, 26-46.

Escudero Muñoz, J. M. (200I): "La educación y la sociedad de la información: cuestiones de contexto y bases para un diálogo necesario", en Blázquez Entonado, F. (coord.): Sociedad de la información y educaci4óon. Badajoz: Junta de Extremadura. 
España. Constitución Española de I978, Boletín Oficial del Estado, 29 de diciembre de I978, núm. 3 II 6, pp. 293 I3-29424.

España. Ley Orgánica 2/2006, de 3 de mayo, de Educación, Boletín Oficial del Estado, 4 de mayo de 2006, núm. I06, pp. I7I 58-I7207.

España. Ley Orgánica 8/2013, de 9 de diciembre, para la mejora de la calidad educativa, Boletín Oficial del Estado, ro de diciembre de 2013, núm. 295, pp. 97858 -9792I.

España. Orden ECI/3854/2007, de 27 de diciembre, por la que se establecen los requisitos para la verificación de los títulos universitarios oficiales que habiliten para el ejercicio de la profesión de Maestro en Educación Infantil, Boletín Oficial del Estado, 29 de diciembre de 2007, núm. 3I2, pp. 53735-53738.

España. Orden ECI/3857/2007, de 27 de diciembre, por la que se establecen los requisitos para la verificación de los títulos universitarios oficiales que habiliten para el ejercicio de la profesión de Maestro en Educación Primaria, Boletín Oficial del Estado, 29 de diciembre de 2007, núm. 3I2, pp. 53747-53750.

España. Orden ECI/38 58/2007, de 27 de diciembre, por la que se establecen los requisitos para la verificación de los títulos universitarios oficiales que habiliten para el ejercicio de las profesiones de Profesor de Educación Secundaria Obligatoria y Bachillerato, Formación Profesional y Enseñanzas de Idiomas, Boletín Oficial del Estado, 29 de diciembre de 2007, núm. 3 I2, pp. 5375 I-53753.

España. Real Decreto I494/2007, de I 2 de noviembre, por el que se aprueba el Reglamento sobre las condiciones básicas para el acceso de las personas con discapacidad a las tecnologías, productos y servicios relacionados con la sociedad de la información y medios de comunicación social, Boletín Oficial del Estado, 2I de noviembre de 2007, núm. 279, pp. 47567-47572.

España. Real Decreto 696/1995, de 28 de abril, de ordenación de la educación de alumnos con necesidades educativas especiales, Boletín Oficial del Estado, 2 de junio de I995, núm. I3 I, pp. I6I79-I6I 85 .
España. Real Decreto Legislativo I/20I3, de 29 de noviembre, por el que se aprueba el Texto Refundido de la Ley General de derechos de las personas con discapacidad y de su inclusión social, Boletín Oficial del Estado, 3 de diciembre de 20I3, núm. 289, pp. $95635^{-}$ 95673 .

Fromm, E. (2009): El miedo a la libertad, Barcelona: Paidós.

Frondizi, R. (1972): ¿Qué son los valores? $3^{a}$ ed., México: Fondo de Cultura Económica.

García Molina, J. (coord.) (20I3): Exclusiones, discursos, politicas y profesiones, Barcelona: Universitat Oberta de Catalunya.

Iyanga Pendi, A. (2003): Política de la educación y globalización neoliberal, Valencia: Universitat de València.

Lledó Carreres, A. y Arnaiz Sánchez, P. (2010): "Evaluación de las prácticas educativas del profesorado de los centros escolares: indicadores de mejora desde la educación inclusiva”. Revista Iberoamericana sobre Calidad, Eficacia y Cambio en Educación, 5 (8): 96-I09.

López-Torrijo, M. (2015): La integración de alumnos con necesidades educativas especificas. La escuela de todos: hitos dificultades y esperanzas en la única escuela posible (en línea). <http://roderic. uv.es/bitstream/handle/I05 50/40840/ La \% 2oescuela \% 2ode \% 2otodos \% 2c\% 20 hitos $\%$ zorealidades $\%$ zoy $\%$ zoesperanzas.... pdf? sequence $=\mathrm{I} \&$ is Allowed $=\mathrm{y}>$, acceso $20 \mathrm{de}$ febrero de 2016.

López-Torrijo, M. (2005): "Personas, derechos y servicios. Razones de una ley, razones de un cambio”, en: López-Torrijo, M. y Carbonell Peris, R. (coords.): La integración educativa y social. Barcelona: Ariel.

López-Torrijo, M. (200I): “Tendencias y desafíos de la Educación Especial”, en Lázaro, L. M. (ed.): Problemas y desafios para la educación en el siglo XXI en España y América Latina. Valencia: Universitat de València. 
López-Torrijo, M. (I999): Textos para una Historia de la Educación Especial $2^{a}$ ed., Valencia: Tirant lo Blanch.

López-Torrijo, M. (1993): La integración escolar. Análisis del desarrollo legislativo, Valencia: Universitat de València.

López-Torrijo, M. y Mengual-Andrés, S. (20I 5 ): "An Attack on Inclusive Education in Secondary Education. Limitations in Initial Teacher Training in Spain". New Approaches in Educational Research, 4 (I): 9-I7.

Orwell, G. (I961): 1984. New York: Signet Classic.

Pitarch Navarro, A. y Ruiz Cortina, J. J. (2009): Epicuro Séneca. Carta a Meneceo Sobre la vida feliz, Valencia: Diálogo.

Robinson, K. y Harris, A. L. (20I4): The broken compass: Parental involvement with children's education, Cambridge: Harvard University Press.

Sánchez Palomino, A. (2007): "Investigación sobre la formación inicial del profesorado de educación secundaria para la atención educativa a los estudiantes con necesidades especiales”. Revista Interuniversitaria de Formación del Profesorado, 2I (2/3): I49-I8I.

Sánchez Palomino, A. (I997): "Formación inicial del profesorado de educación secundaria y atención a los alumnos con necesidades educativas especiales". Revista Interuniversitaria de Formación del Profesorado, I I (I): 67-8I.

Sandoval Mena, M. et al. (20I2): "Análisis y valoración crítica de las funciones del profesorado de apoyo desde la educación inclusiva”. Revista de Educación, Número extraordinario: I I7-I 37 .

Savater, F. (I997): El valor de educar, Barcelona: Ariel.

Sennett, R. (2010): La corrosión del carácter. Las consecuencias personales del trabajo en el nuevo capitalismo, Barcelona: Anagrama.

Sennett, R. (2006): La cultura del nuevo capitalismo, Barcelona: Anagrama.

Unesco (201 5): Declaración de Incheon. Educación 2030: Hacia una educación inclusiva y equitativa de calidad y un aprendizaje a lo largo de la vida para todos (en línea). <http:// es.unesco.org/world-education-forum-20I $5 /$ about-forum/declaracion-de-incheon $>$, acceso 20 de febrero de 2016.

Unesco (2009): Towards Inclusive Education for Children with Disabilities: A Guideline (en línea). <http://www.uis.unesco.org/Library/ Documents/disabchildo9-en.pdf $>$, acceso $20 \mathrm{de}$ febrero de 2016.

Unesco (2005): Guidelines for inclusion. Ensuring access to education for all (en línea). <http://unesdoc.unesco.org/ images/OOI 4/OOI402/I40224e.pdf $>$, acceso 20 de febrero de 2016 .

Unesco (200I): Open File on Inclusive Education. Support Materials for Managers and Administrators (en línea). <http://unesdoc. unesco.org/images/oOI 2/OOI $252 /$ I 25237 eo. pdf $>$, acceso 20 de febrero de 2016.

Unesco (1990): World declaration on education for all and Framework for action to meet basic learning needs (en línea). <http://unesdoc. unesco.org/images/0009/000975/097552e.pdf>, acceso 20 de febrero de 2016 .

Unicef (20I I): How to design and manage Equity-focused evaluations (en línea). <http:// evalpartners.org/sites/default/files/EWP ${ }_{5}$ Equity_focused_evaluations.pdf $>$, acceso $20 \mathrm{de}$ febrero de 2016.

United Nations (I994): Standard Rules on the Equalization of Opportunities for Persons with Disabilities. <http://www. un.org/es/comun/docs/index.asp?symbol=A/ RES/48/96\&referer=http://www.un.org/ depts/dhl/resguide/r48_resolutions_table_ es.htm\&Lang=E $>$, acceso 20 de febrero de 2016.

United Nations (1975): Declaration of the Rights of Disabled persons (en línea). <http://www. un.org/en/ga/search/view_doc.asp?symbol=A/ $\mathrm{RES} / 3447(\mathrm{XXX})>$, acceso 20 de febrero de 2016.

Vega Fuente, A (2003): La educación social ante la discapacidad, Málaga: Aljibe. 
Vives, J. L. (I78I): Tratado del socorro de los pobres (en línea) <https://books.google.es/ books?hl=es\&lr=\&id=7Su-XINaTJwC\&oi=fn $\mathrm{d} \& \mathrm{pg}=\mathrm{PR} I \& \mathrm{dq}=$ Tratado+del + socorro+de+lo s+pobres\&ots=UEnV6 IfLJ7 \&sig=ExYlcBMe $\mathrm{dKxC6}{ }_{4}$ RFPviKNCY6GIw\#v=onepage $\& \mathrm{q}=\mathrm{T}$ ratado $\%$ 2odel $\%$ 2osocorro $\%$ 2ode $\% 20 l$ os $\% 20$ pobres $\& \mathrm{f}=\mathrm{false}>$, acceso 20 de febrero de 20 I 6 .

Warnock, M. (I987): "Encuentro sobre necesidades educativas especiales". Revista de Educación, número extraordinario: 45-74.
Watzlawick, P. et al. (2012): Teoría de la comunicación humana. Interacciones, patologías y paradojas. Barcelona: Herder.

Who (20I I): World report on disability. Malta: World Health Organization.

Who (2001): International Classification of Functioning, Disability and Health (en línea). $<$ http://psychiatr.ru/download/I 3 I 3 ?view= = \& name=ICF_I 8.pdf>, acceso 20 de febrero de 2016. 